\title{
Multi-Objective Optimization Control for the Aerospace Dual-Active Bridge Power Converter
}

\author{
Tao Lei ${ }^{1, *}$, Cenying $\mathrm{Wu}^{2}$ and Xiaofei Liu ${ }^{1}$ \\ 1 Key Laboratory of Aircraft Electric Propulsion Technology, \\ Ministry of Industry and Information Technology of China, Northwestern Polytechnic University, \\ Xi'an 710072, China; xiaofeiliu@mail.nwpu.edu.cn \\ 2 Shenyang Aircraft Design and Research Institute, Shenyang 110034, China; wucenying@163.com \\ * Correspondence: 1ttiger@nwpu.edu.cn
}

Received: 27 March 2018; Accepted: 25 April 2018; Published: 7 May 2018

\begin{abstract}
With the development of More Electrical Aircraft (MEA), the electrification of secondary power systems in aircraft is becoming more and more common. As the key power conversion device, the dual active bridge (DAB) converter is the power interface for the energy storage system with the high voltage direct current (HVDC) bus in aircraft electrical power systems. In this paper, a DAB DC-DC converter is designed to meet aviation requirements. The extended dual phase shifted control strategy is adopted, and a multi-objective genetic algorithm is applied to optimize its operating performance. Considering the three indicators of inductance current root mean square root (RMS) value, negative reverse power and direct current (DC) bias component of the current for the high frequency transformer as the optimization objectives, the DAB converter's optimization model is derived to achieve soft switching as the main constraint condition. Optimized methods of controlling quantity for the DAB based on the evolution and genetic algorithm is used to solve the model, and a number of optimal control parameters are obtained under different load conditions. The results of digital, hard-in-loop simulation and hardware prototype experiments show that the three performance indexes are all suppressed greatly, and the optimization method proposed in this paper is reasonable. The work of this paper provides a theoretical basis and researching method for the multi-objective optimization of the power converter in the aircraft electrical power system.
\end{abstract}

Keywords: double active bridge converter (DAB); multi-objective optimization; evolution and genetic algorithm

\section{Introduction}

The aerospace industry is promoting the use of more electrical technology to enhance the performance and increase the reliability of aircraft power systems and secondary power subsystems instead of hydraulic, pneumatic systems. High voltage DC systems (HVDCs) are very popular in aircraft electric power systems because of their simpler equipment and significant energy savings. This technology requires high power density, reliable DC-DC converter for the application of battery storage power supplies to mission critical aerospace situations, e.g., actuators and avionics. $\mathrm{DAB}$ converters, as the interface of energy storage devices, have become a research hotspot $[1,2]$. The DAB converter has been popular among researchers over the last ten years due to its high performance, high efficiency, galvanic isolation and soft-switching property [3,4]. A DAB converter's topology is shown in Figure 1. Because of the extra power switching devices, the pressure and flow capacity of the power switching are strong, so a larger power can be transmitted [5], but there are also some shortcomings [6], such as the increase of the inductance current value will increase the switching loss and switching stress make the switching device become damaged easily. In addition, there is a 
negative power transmission in the $\mathrm{DAB}$ converter, the circulation loss is large, so the transmission power peak in the circuit is increased, and the weight and volume of the transformer will be increased, which is not acceptable in aerospace context. The saturation of high frequency transformers will be caused by the DC bias component existing in the inductance current under the load transient variation, therefore, it how to optimize the dual active bridge DC-DC converter in aircraft electrical power systems has important practical significance.

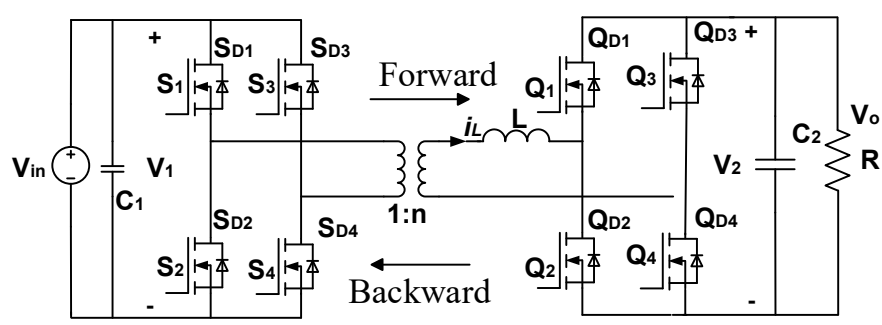

Figure 1. The topology of a DAB converter.

At present, there are four main DAB converter topologies: single-phase/three-phase voltage source, single-phase current source, and single-phase resonant type. Control methods mainly focus on the phase shift control strategy, including single phase shift, double phase shift, expansion double phase shift, triple phase shift, phase shift plus pulse width modulation (PWM) hybrid control strategy, and model predictive control methods [7-13]. The single phase shift control strategy is simple and easy to realize, but the range of output power is narrow and reverse power exists. Multiple phase-shifting control methods have increased control variables, and the combination selection and calculation of multivariable is the key points to controlling the performance of DAB converters.

So far, many efforts have been made to improve the performance of DAB converters. Nevertheless, design considerations for high frequency DAB converter transformers are primarily concerned with core material, loss minimization, and suppression of DC bias components. The concept of global optimal condition (GOC) equations is proposed in [14] to derive the closed form of analytic expressions of an optimal modulation scheme that makes the DAB converter operate with minimized root-mean-square (RMS) current during whole power range with different operating modes. Aiming to improve the performance features of conventional two-level DAB converters, reference [15] presented a three-level neutral-point-clamped (NPC) DAB DC-DC converter. A set of decoupled optimization problems is formulated as a function of the available modulation degrees of freedom to minimize the predominant converter losses. A current-stress-optimized switching strategy is applied in [16] based on Isolated Bidirectional DC-DC Converter (IBDC) to minimize the current stress, improve the system efficiency, and increase system power transmission capability, and these performances are particularly effective for operation conditions with high voltage conversion ratio and light load. The model predictive control algorithm is used to improve the efficiency of DAB converter in [17]. A unit prediction horizon binary search-based nonlinear model predictive control (MPC) of phase shift full-bridge DC-DC converter is presented in [18], which offers faster optimization solution for MPC, thereby facilitating high frequency operation of the converter, thus the output voltage regulation performance is improved. By investigating the influence of the perturbation of control variables on the transferred power and the RMS value of the inductance current, a global optimal condition is deduced in [19]. A multi-objective optimization routine is proposed to systematically assess the concepts with respect to the efficiency, power density, and the costs with the 3 and 5-Level DAB converter in [20]. A detailed power loss model of a DAB converter was derived in this paper, but the dynamic control methods based on optimization are not regarded. A minimized RMS current operation methods for the dual active half-bridge (DAHB) DC-DC converters is presented in [21]. In this paper, closed-form expressions corresponding to two control strategies are derived which minimize RMS value must be 
consistent value of transformer current at a given power with and without zero voltage switching (ZVS) operation. The other optimal objectives are not discussed in this paper.

A novel method which can achieve the multi-objective optimization for the performance in DAB converters is proposed in this paper. Using this genetic-algorithm optimization methods based on the dual phase shift control, the performance features of DAB converters such as high efficiency, low dc bias component and low stress to switching device can be realized considering the constraints such as ZVS conditions in DAB converter.

This paper is organized as follows: Section 2 introduces the operating principle of the DAB converter, from two aspects of steady state and transient state, and some power characteristic formulas are derived. In Section 3, the multi-objective optimization model is established on the basis of the Section 2, and the genetic algorithm is used to solve the optimal control variable for the power mode of DAB converter. Simulation and hard in loop (HIL) experimental results for optimization on the platform of software platform MATLAB/Simulink 2012 (The MathWorks Ltd, Natick, MA, USA) and HIL platform typhoon 600 are delivered in Section 4. The experimental verification is described in Section 5. Finally, Section 6 presents our conclusions.

\section{The Establishment of Optimization Model}

In the DAB converter's power transmission process, the coupled inductor $L$ plays a very important role, transmitting power either from the low voltage side to the high voltage side of the converter, or from the high side to the low side, it uses of an inductance $L$ is needed as the power transmission medium. Therefore, the inductance selection has a great influence on the operating ability of the DAB converter. The research on the input and output characteristics of the DAB converter will start with the analysis of the inductance current $i_{L}$. Figure 2 is the main circuit waveform including $i_{L}$ in a switching cycle. The $V_{H 1}$ and $V_{H 2}$ are the primary side voltage and secondary side voltage of high frequency transformers in Figure 2. Align equations and symbols

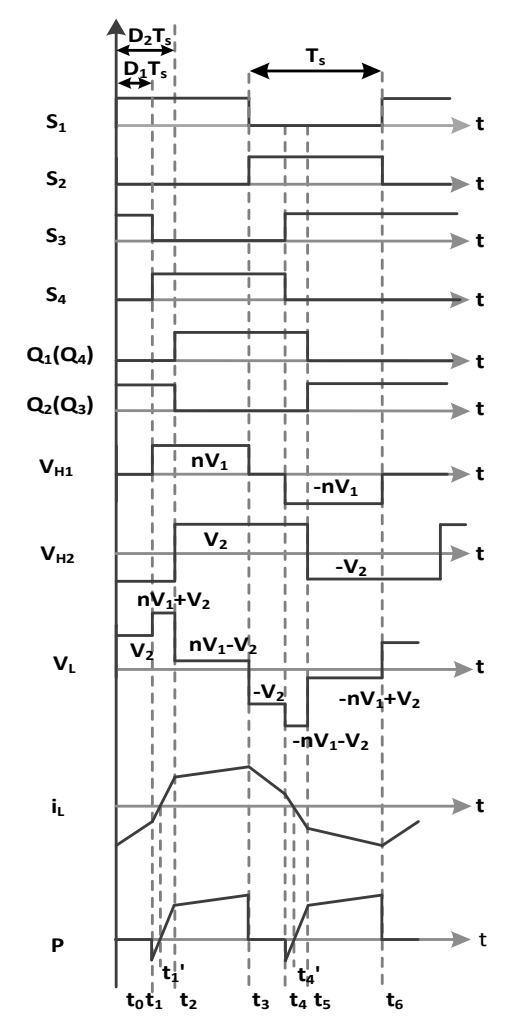

Figure 2. The main circuit waveform in one cycle. 


\subsection{Steady State Performance Analysis}

According to the principle of current ampere second equilibrium, the average of the inductance current is 0 within a switching period:

$$
\int_{0}^{2 T_{S}} i_{L}(\mathbf{t}) d t=0
$$

The peak current of each time point can be derived from Figure 2:

$$
\left\{\begin{array}{l}
i_{0}=i_{L}\left(t_{0}\right)=\frac{T_{s}}{2 L}\left(n V_{1} D_{1}-n V_{1}-2 V_{2} D_{2}+V_{2}\right) \\
i_{1}=i_{L}\left(t_{1}\right)=\frac{T_{s}}{2 L}\left(n V_{1} D_{1}-n V_{1}+2 V_{2} D_{1}-2 V_{2} D_{2}+V_{2}\right) \\
i_{2}=i_{L}\left(t_{2}\right)=\frac{T_{s}}{2 L}\left(-n V_{1} D_{1}+2 n V_{1} D_{2}-n V_{1}+V_{2}\right) \\
i_{3}=i_{L}\left(t_{3}\right)=\frac{T_{s}}{2 L}\left(-n V_{1} D_{1}+n V_{1}+2 V_{2} D_{2}-V_{2}\right) \\
i_{4}=i_{L}\left(t_{4}\right)=\frac{T_{s}}{2 L}\left(-n V_{1} D_{1}+n V_{1}-2 V_{2} D_{1}+2 V_{2} D_{2}-V_{2}\right) \\
i_{5}=i_{L}\left(t_{5}\right)=\frac{T_{s}}{2 L}\left(n V_{1} D_{1}-2 n V_{1} D_{2}+n V_{1}-V_{2}\right)
\end{array}\right.
$$

Because the magnitude of the effective current of inductor current directly affects the copper consumption of transformer and the state loss of semiconductor device [22], it is necessary to derive the expression of the RMS value square of inductance current as follows:

$$
i_{L(r m s)}^{2}=\frac{1}{2 T_{s}} \int_{0}^{2 T_{s}} i_{L}^{2}(t) d t=\frac{T_{s}^{2}}{6 L^{2}}\left\{\begin{array}{l}
D_{1}\left(\begin{array}{l}
n V_{1} D_{1}-n V_{1} D_{2} \\
-V_{2} D_{2}
\end{array}\right)\left(\begin{array}{l}
n V_{1} D_{1}+2 n V_{1} D_{2}-3 n V_{1} \\
+2 V_{2} D_{1}-4 V_{2} D_{2}+3 V_{2}
\end{array}\right) \\
+D_{2}\left(\begin{array}{l}
n V_{1} D_{1}-n V_{1}+V_{2} D_{1} \\
-2 V_{2} D_{2}+V_{2}
\end{array}\right)\left(\begin{array}{l}
n V_{1} D_{1}-2 n V_{1} D_{2} \\
+n V_{1}-2 V_{2} D_{1}-V_{2}
\end{array}\right) \\
+\frac{1}{2}\left[\left(\begin{array}{l}
-n V_{1} D_{1}+2 n V_{1} D_{2} \\
-n V_{1}+V_{2}
\end{array}\right)^{2}+\left(\begin{array}{l}
-n V_{1} D_{1}+n V_{1} \\
+2 V_{2} D_{2}-V_{2}
\end{array}\right)\right. \\
\left.+\left(\begin{array}{c}
-n V_{1} D_{1}+2 n V_{1} D_{2} \\
-n V_{1}+V_{2}
\end{array}\right)\left(\begin{array}{l}
-n V_{1} D_{1}+n V_{1} \\
+2 V_{2} D_{2}-V_{2}
\end{array}\right)\right]
\end{array}\right\}
$$

In order to reduce the loss of the converter, the minimum RMS value of inductance current was chosen as one of the optimization objective functions.

The average output power can be calculated as follow:

$$
P_{O}=\frac{1}{T_{s}} \int_{0}^{T_{s}} V_{H 1} i_{L}(t) d t=\frac{n V_{1} V_{2} T_{s}}{2 L}\left(2 D_{1} D_{2}-2 D_{2}^{2}+2 D_{2}-D_{1}^{2}-D_{1}\right)
$$

and it can be concluded that, when $D_{1}=0, D_{2}=0.5$, the maximum average output power is:

$$
P_{\text {max }}=\frac{n V_{1} V_{2}}{8 f_{s} L}
$$

When the output load is $R, P_{O}$ can also be expressed as:

$$
P_{O}=\frac{V_{2}^{2}}{R}
$$

Combining with Equation (4) we can obtain:

$$
V_{2}=\frac{n V_{1} R}{4 f_{s} L}\left(2 D_{1} D_{2}-2 D_{2}^{2}+2 D_{2}-D_{1}^{2}-D_{1}\right)
$$




$$
I_{2}=\frac{n V_{1}}{4 f_{s} L}\left(2 D_{1} D_{2}-2 D_{2}^{2}+2 D_{2}-D_{1}^{2}-D_{1}\right)
$$

Because the DAB converter requires $28 \mathrm{~V}$ DC voltage output, $V_{2}=28 \mathrm{~V}$ will be one of the constraints of this optimization model.

\subsection{Reverse Power and Transient DC Bias Component Analysis}

It can be seen from Figure 2 that in the power transmission process, negative power has a reverse power flow direction. The negative power is a kind of reactive power, it increases the apparent power of the power transmission process in the circuit, meanwhile the losses of the circuit and devices are also increased. The increase of the power loss of the whole power converter can further reduce the efficiency of power transmission of the DAB converter. When the reverse negative power decreases, the peak value of the transmitted power also decreases, which reduces the switching stress of the power switching device and reduces the demand for the high frequency transformer capacity and thus reduces the power volume of the transformer under design. Therefore, in order to improve the performance of the converter, it is necessary to reduce the reverse negative power of the converter as much as possible.

Deduce the time $t_{1}^{\prime}$ of the inductance current $i_{L}$ is 0 , that is:

$$
\frac{n V_{1}+V_{2}}{L} t_{1}^{\prime}-t_{1}+i\left(t_{1}\right)=0
$$

We obtain:

$$
t_{1}^{\prime}=\frac{\left(n V_{1} D_{1}+n V_{1}+2 V_{2} D_{2}-V_{2}\right) T_{s}}{2\left(n V_{1}+V_{2}\right)}
$$

The reverse negative power can be obtained from this:

$$
P_{-a v g}=\frac{1}{T_{S}} \int_{t_{1}}^{t_{1}^{\prime}} n V_{1}\left|i_{L}(t)\right| d t
$$

Bring Equation (10) into Equation (11) and can be obtained:

$$
P_{-a v g}=\frac{n V_{1} T_{s}}{8 L\left(n V_{1}+V_{2}\right)}\left[n V_{1}\left(1-D_{1}\right)+V_{2}\left(2 D_{2}-2 D_{1}-1\right)\right]^{2}
$$

It can be seen that we can suppress the reverse negative power by optimizing the combination of $D_{1}$ and $D_{2}$, thus we choose $P_{-a v g}$ minimum as one of the optimization objective functions.

In the circuit operating process, because of the difference of the parameters of the components or the asymmetry of circuit layout, the on-state voltage drop is not equal, the difference of the turn off time when the power switch is turned off, the power transistor trigger factors of pulse signal is asymmetric, and the current waveform of the high frequency transformer in the DAB converter cannot have ideal symmetry, therefore, the dc bias becomes a practical issue because of the inconsistency between theory and practice. According to these factors, the magnetization curve of the iron core is not symmetric about the origin of coordinates, and the magnetization curve is usually a nonlinear curve, so when there is very serious dc bias current, iron core will enter a saturation state, causing the magnetizing current to increase significantly, thus increasing the loss of the converter and even causing damage to the switching device [23-25].

Therefore, it is necessary to analyze and suppress this bias component. According to [16], the expression of DC bias is deduced to be used for subsequent suppression. The converter in positive mode (in buck mode), using a sudden increase in output power as an example, as shown in Figure 3, $t_{0}$ moments ago, the converter stability and inductor current waveform were symmetrical, at time $t_{0}$, 
with a power surge, if the converter internal and external shift duty noted before the power surge are $D_{1}$ and $D_{2}$, respectively, after the power mutation, the converter internal and external shift duty ratio are refreshed to $D_{1}{ }^{\prime}$ and $D_{2}{ }^{\prime}$ respectively, $0<D_{1}<D_{1}{ }^{\prime}$ and $0<D_{2}<D_{2}{ }^{\prime}$, then, with the increase of phase angle, the maximum value of the inductor current increases, and the DC bias component will exist for even a few cycles.

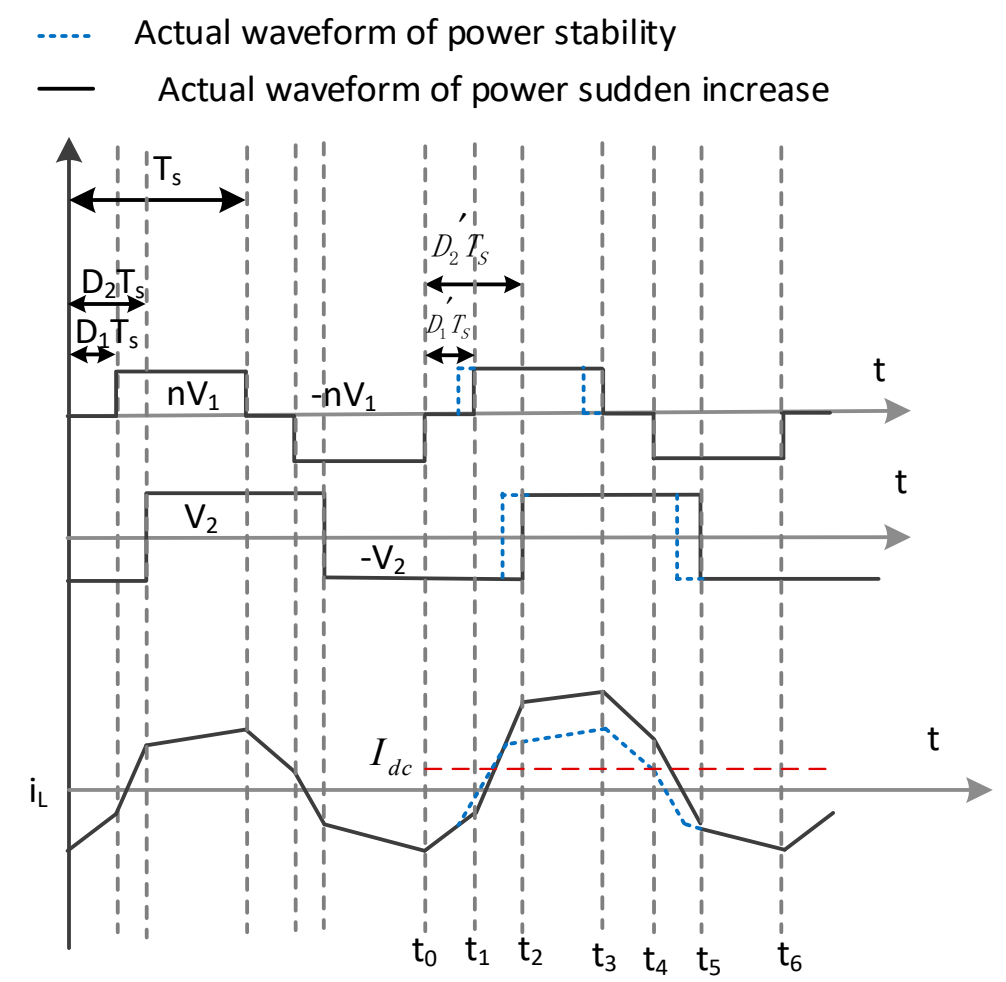

Figure 3. Basic waveforms before and after power changing dynamically.

DC bias component can be calculated according to the first cycle of:

$$
I_{d c}=\frac{1}{2 T_{s}} \int_{0}^{2 T_{s}} i_{L}(t) d=\frac{2 T_{s}}{L}\left[-n V_{1}\left(D_{1}^{\prime}-D_{1}\right)+2 V_{2}\left(D_{2}^{\prime}-D_{2}\right)\right]
$$

After the analysis above, this paper will select the minimum $I_{d c}$ as one of the optimization objective functions.

In order to realize the high frequency, high efficiency and low loss operation for the converter, soft switching technology is often used. The requirements of the DAB converter to implement ZVS are:

$$
\left\{\begin{array}{l}
i\left(t_{1}\right) \leq 0 \\
i\left(t_{2}\right) \geq 0
\end{array}\right.
$$

Substituting Equation (2) into Equation (14), and the following simplification can be obtained:

$$
\left\{\begin{array}{c}
n V_{1} D_{1}-n V_{1}+2 V_{2} D_{1}-2 V_{2} D_{2}+V_{2} \leq 0 \\
-n V_{1} D_{1}+2 n V_{1} D_{2}-n V_{1}+V_{2} \geq 0
\end{array}\right.
$$

Equation (15) will be considered as the constraint condition of the optimization model.

According to the requirements of Table 1, some function 3-D diagrams are drawn as follows. 
Table 1. Circuit parameters in the rated state converter.

\begin{tabular}{cc}
\hline Parameter Name & Rated Value \\
\hline High voltage side voltage $V_{1}$ & $270 \mathrm{~V}$ \\
Low voltage side voltage $V_{2}$ & $28 \mathrm{~V}$ \\
High voltage side capacitance $C_{1}$ & $10 \mu \mathrm{F}$ \\
Low voltage side capacitance $C_{2}$ & $1000 \mu \mathrm{F}$ \\
Transformer ration & $270: 80$ \\
Coupled inductor $L$ & $12 \mu \mathrm{H}$ \\
Load resistance $R$ & $1.568 \Omega$ \\
Input equivalent resistance $R_{S}$ & $0.1 \Omega$ \\
switching frequency $f_{S}$ & $40 \mathrm{kHz}$ \\
\hline
\end{tabular}

From Figure 4a, it can be seen that under the premise of $D_{1}<D_{2}<1$, the closer the $D_{1}$ and $D_{2}$ are, the smaller the $i_{L(r m s)}^{2}$ is. This result can be used as one of the screening bases for the $D_{1}$ and $D_{2}$ combination.

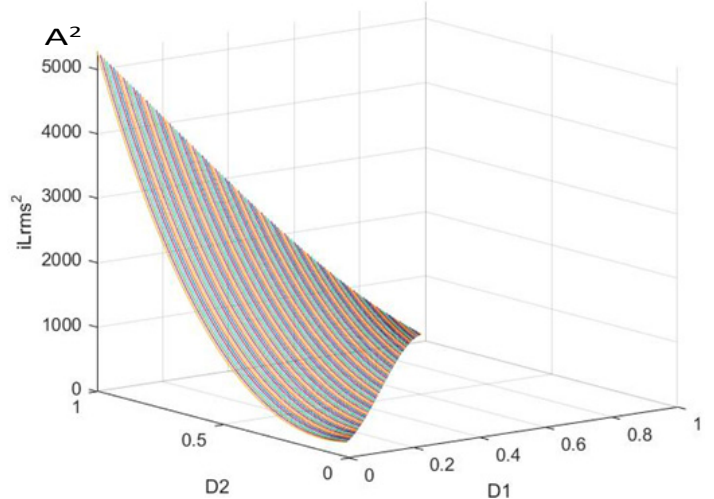

(a)

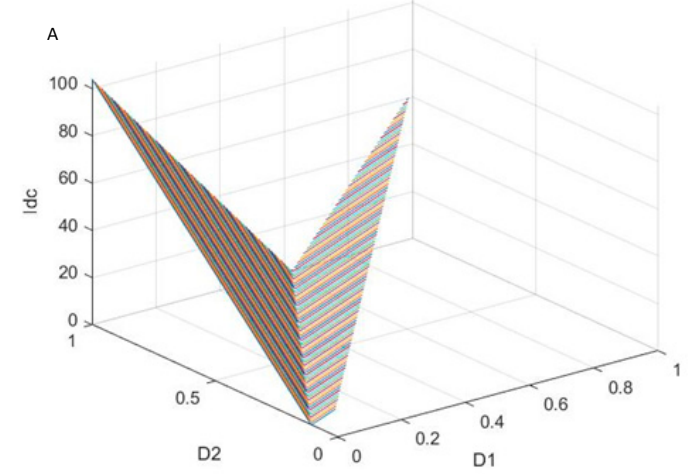

(c)

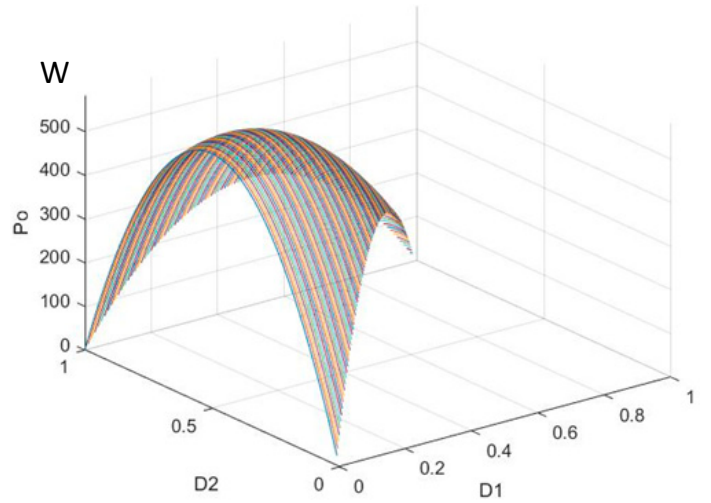

(b)

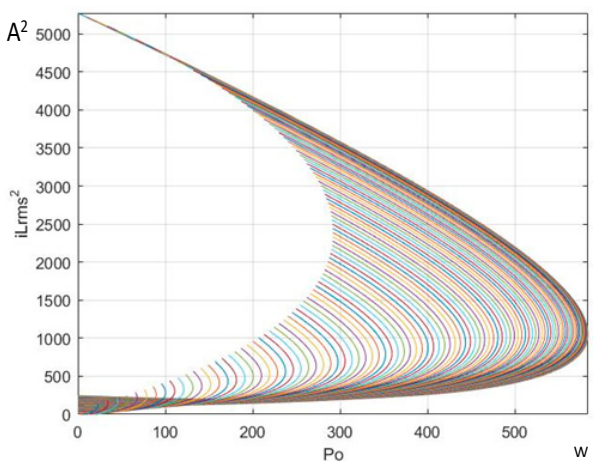

(d)

Figure 4. Function 3-D diagrams according to Table 1. (a) Function diagram of $D_{1}-D_{2}-i_{L(r m s)}^{2}$; (b) Function diagram of $D_{1}-D_{2}-P_{0}$; (c) Function diagram of $D_{1}-D_{2}-I_{d c}$; (d) Function diagram of $P_{0}-i_{L(r m s)}^{2}$.

Figure $4 \mathrm{~b}$ proves that when $D_{1}=0, D_{2}=0.5$

$$
P_{\text {max }}=\frac{n V_{1} V_{2}}{8 f_{s} L}=583 \mathrm{~W}
$$

It can be seen in Figure 4c, that when $0<D_{1}<0.6,0.1<D_{2}<1, I_{d t}$ is smaller this range can be used as one of the screening criteria. 
As can be seen from Figure $4 \mathrm{~d}$, each $P_{O}$ corresponds to many $i_{L(r m s)}^{2}$, so it is necessary to limit $i_{L(r m s)}^{2}$. According to the rightmost point of the image, $i_{L(r m s)}^{2}$ should not exceed 1000 when solving the optimization model. This result will be used as an additional constraint.

\section{The Optimal Solution of Power Model of DAB Converter}

Based on the above analysis, the optimization model of the DAB converter based on the extended phase shift control can be obtained according to the above analysis.

Design variables: the interior angle $x_{1}=D_{1}$, and the external angle $x_{2}=D_{2}$, where: $k_{1}=T_{S}=$ $1 / 80000, k_{2}=1.2 e-5, k_{3}=n V_{1}=80, k_{4}=V_{2}=28, k_{5}=P_{0}=500$.

Objective function:

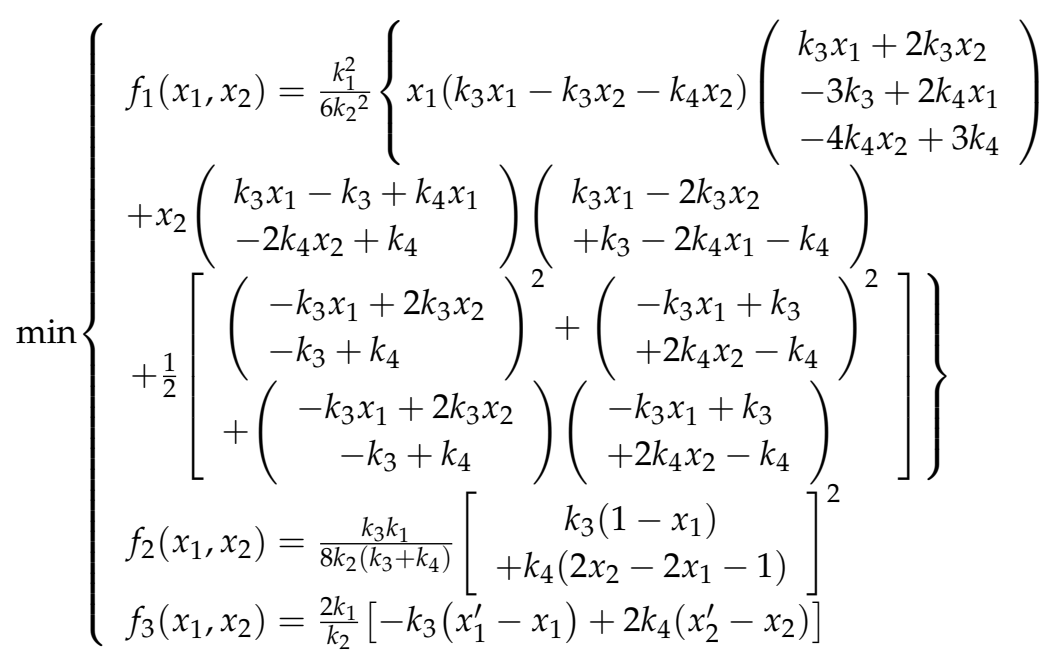

Constraints:

$$
\left\{\begin{array}{l}
0<x_{1}<x_{2}<1 \\
f_{1}\left(x_{1}, x_{2}\right)<1000 \\
-k_{3} x_{1}+2 k_{3} x_{2}-k_{3}+k_{4} \geq 0 \\
k_{3} x_{1}-k_{3}+2 k_{4} x_{1}-2 k_{4} x_{2}+k_{4} \leq 0 \\
\frac{k_{3} k_{4} k_{1}}{2 k_{2}}\left(2 x_{1} x_{2}-2 x_{2}^{2}+2 x_{2}-x_{1}^{2}-x_{1}\right)=k_{5}
\end{array}\right.
$$

Genetic algorithm is an adaptive probability optimization algorithm that solves complex system optimization problems with the help of biological genetics and evolutionary ideas. It does not depend on the research object. Using the multi-objective genetic algorithm in the MATLAB genetic algorithm toolbox, the above models are solved, and a set of internal and external phase shift angles corresponding to the variation of load power are obtained, which is shown in Table 2. The Toolbox's configuration is shown in following: Solver: gamultiobj; Population size: 1000; Pareto front population fraction: 0.02; Generations: 1000; Function tolerance: 1e-8; Constraint tolerance: 0.01 . All the variables and parameters must be normalized. The Pareto front curve for the rated conditions is shown in Figure $5 \mathrm{a}$. The terms $f_{1}$ and $f_{2}$ respectively correspond to the optimized objects. That is the optimization result, which is an important basis for our subsequent simulation and experiments. According to the Table 2, the basic relationship between the load power and phase shift angle $D_{1}, D_{2}$ can be as shown in Figure $5 b, c$. 
Table 2. Optimization results.

\begin{tabular}{cccc}
\hline No. & Power $(\mathbf{W})$ & $\boldsymbol{D}_{\mathbf{1}}$ & $\boldsymbol{D}_{\mathbf{2}}$ \\
\hline 1 & 550 & 0.215 & 0.548 \\
2 & 500 & 0.33 & 0.58 \\
3 & 450 & 0.456 & 0.726 \\
4 & 400 & 0.52 & 0.654 \\
5 & 350 & 0.568 & 0.645 \\
6 & 300 & 0.617 & 0.645 \\
7 & 250 & 0.746 & 0.865 \\
\hline
\end{tabular}

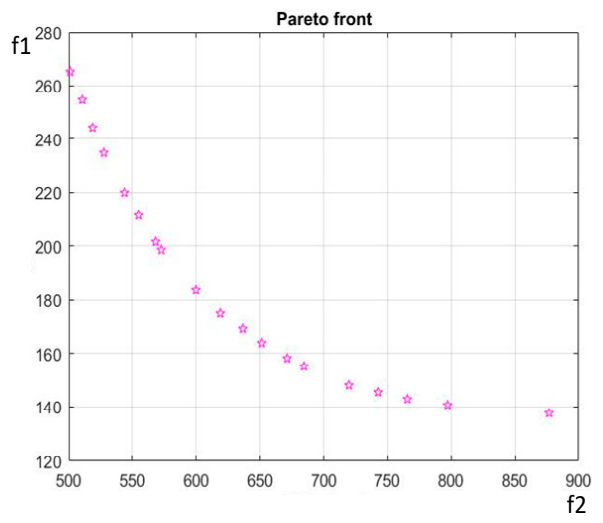

(a)

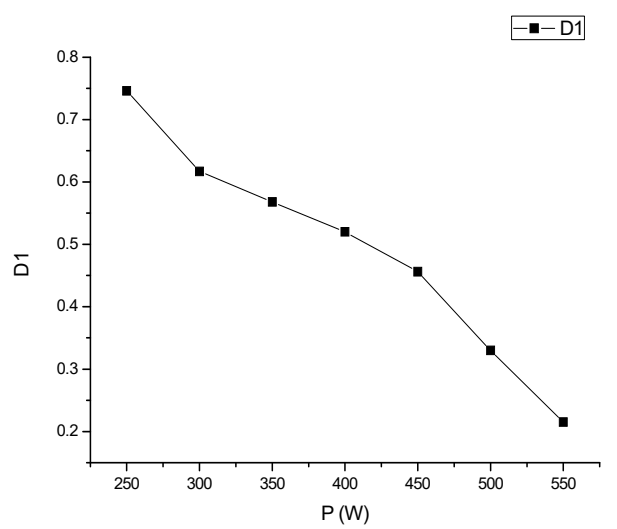

(b)

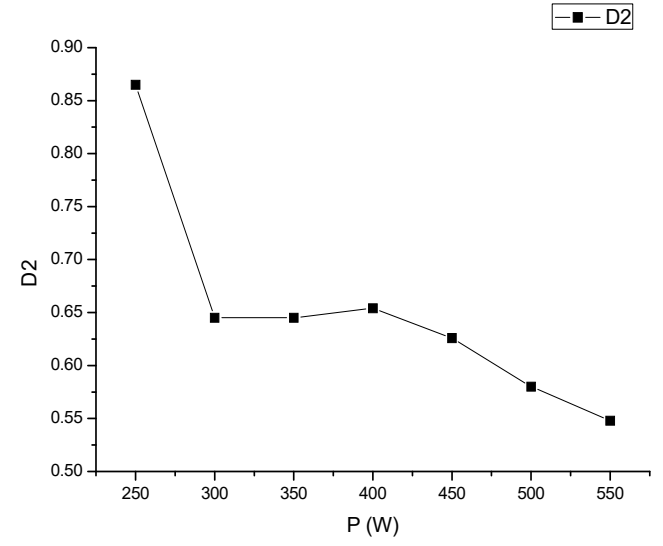

(c)

Figure 5. (a) Pareto front on rated condition (b) Relation curve of $D_{1}$ and power (c) Relation curve of $D_{2}$ and power.

\section{Simulation Verification}

\subsection{MATLAB Simulation Verification}

According to the parameters in Table 1, a DAB converter model based on MATLAB/Simulink is fully run for $0.1 \mathrm{~s}$, whereby the load resistance increases from $1.568 \Omega$ to $3.136 \Omega$ at $0.05 \mathrm{~s}$, and the transmission power is changed from the rated $500 \mathrm{~W}$ to $250 \mathrm{~W}$, comparing the performance indexes of DAB converter, in contrast to the traditional proportion integration differentiation (PID) control mode. The closed-loop control blocks for the DAB converters can be realized by the look-up table from the control variable of Table 2 under the different load situations by the offline optimization method, so the linear extrapolation methods algorithm can be used for the close-loop controller in look-up table to meet the power demand between the given load power points in Figure 2. The control block diagram of the DAB converter based on the optimal control methods is shown in Figure 6a and 
the flow chart of the control algorithm is shown in Figure 6b. From Figure 6a, the offline optimal phase shift variables $D_{1}$ and $D_{2}$ can be selected by the load power computation. The control algorithm based on the Figure $6 \mathrm{~b}$ is very simple and high efficiency. It is very easily realized in the digital signal processing (DSP) controller platform.

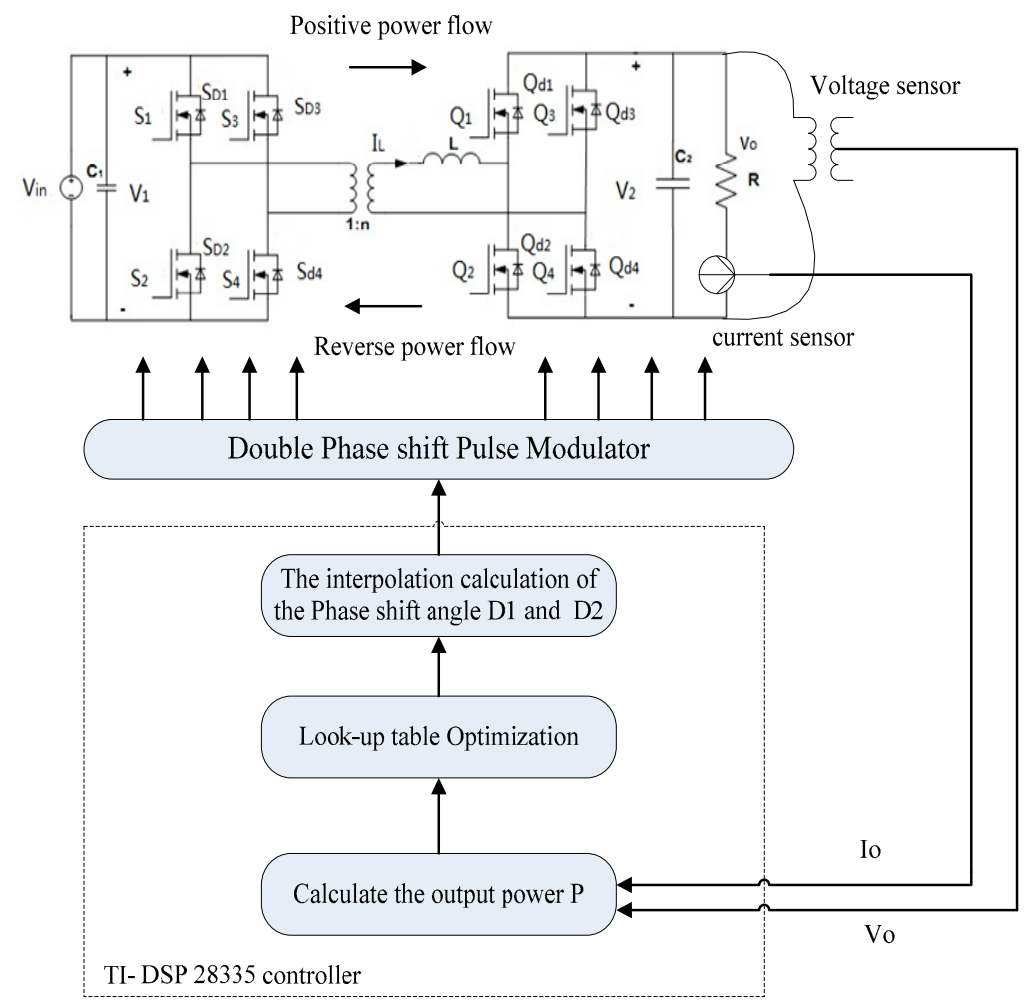

(a)

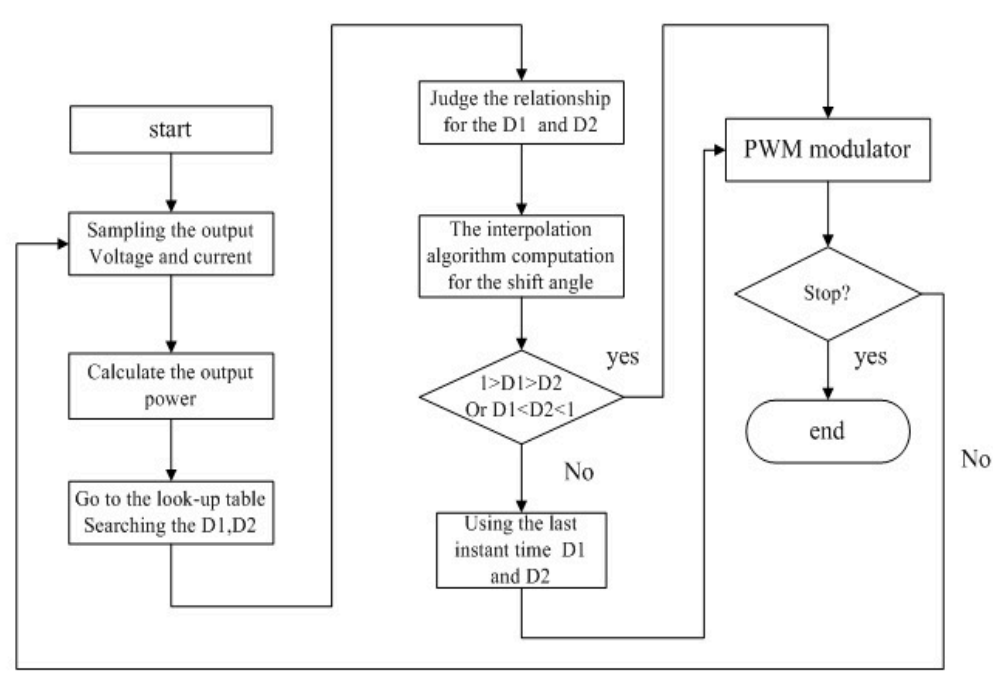

(b)

Figure 6. (a) Proposed control block diagram; (b) The flow chart for the algorithm.

\subsubsection{Transient Output Characteristics}

The output voltage, current waveform and local magnification diagram of the two control mode methods are shown in Figure 7. 

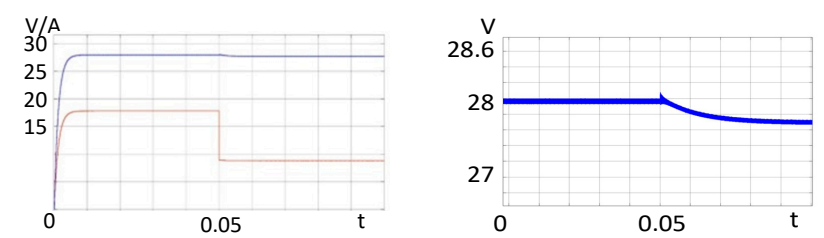

(a)
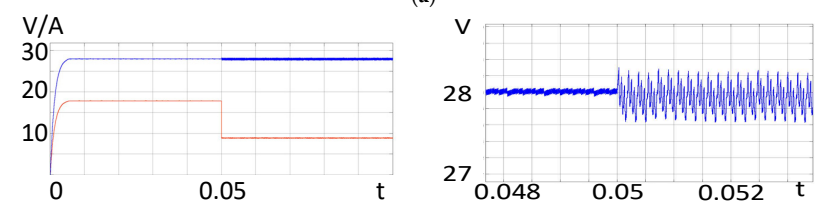

(b)

Figure 7. Output waveform and its amplification

(a) Optimal control mode; (b) Traditional control mode.

One can get from the figures, on the optimal control model, that the response time of the converter is $6 \mathrm{~ms}$, output voltage is stable at $28 \mathrm{~V}$, output current is about $17.86 \mathrm{~A}$, power is $500 \mathrm{~W}$, the system has no overshoot during start-up, voltage ripple is less than $0.1 \mathrm{~V}$, and the ripple ratio is less than $0.36 \%$. When the load mutates, the output voltage has a $0.1 \mathrm{~V}$ overshoot with a rate of about $0.3 \%$, then settles at $27.7 \mathrm{~V}$, about $1 \%$ error, ripple about $0.06 \mathrm{~V}$, with a rate of about $0.2 \%$. In the traditional control mode, when the load is suddenly changed, the output voltage fluctuates rapidly between $27.6 \mathrm{~V}$ and $28.3 \mathrm{~V}$. The ripple peak value reaches $0.7 \mathrm{~V}$, and the ripple ratio is about $2.5 \%$, which seriously affects the stability of the converter output.

\subsubsection{RMS Value of Inductor Current and DC Bias Current Component}

In the two control modes, the waveforms of the inductance current are as shown in Figure 8.

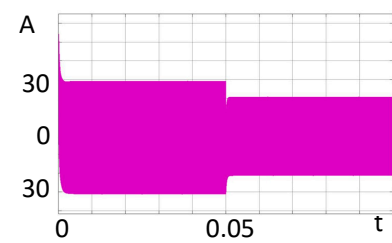

(a)

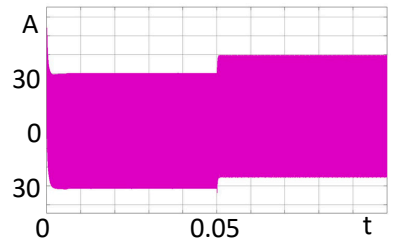

(b)

Figure 8. Inductance current waveform of (a) Optimal control mode; (b) Traditional control mode.

It can be seen from the above diagrams that the peak value of inductance current increases from $60 \mathrm{~A}$ to $65 \mathrm{~A}$ in the traditional control mode when the load is changed. The inductance current waveform is shifted upwards, the forward amplitude is about $40 \mathrm{~A}$, and the negative amplitude is about $-25 \mathrm{~A}$, and no longer has positive and negative symmetry. In the optimal control mode, the current waveform of the inductor still shows positive and negative symmetry, the peak-to-peak value decrease obviously, from $60 \mathrm{~A}$ to $40 \mathrm{~A}$, and the positive and negative amplitude is about $20 \mathrm{~A}$. At the same time, through the MATLAB/Simulink module solution, the RMS value of the inductor current of traditional control mode is $19.91 \mathrm{~A}$, the DC bias component is about $1.146 \mathrm{~A}$, and for the optimal control mode, the RMS value of the inductor current is $16.86 \mathrm{~A}$, the DC bias component is about $0.4893 \mathrm{~A}$, and one can see that the two indexes of the RMS value of the inductor current and DC bias component are significantly improved in optimal control mode compared with the traditional PI control.

\subsubsection{Reverse Negative Power}

The waveform of the transient power of the low voltage side of the transformer under two control modes is shown in Figure 9. 


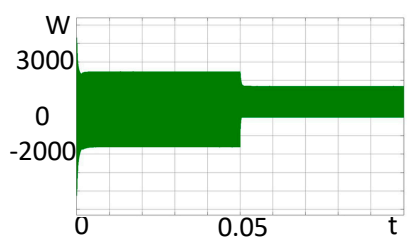

(a)

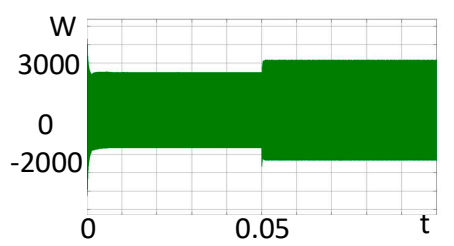

(b)

Figure 9. The waveform of the transient power of the low voltage side of the transformer. (a) Optimal mode; (b) Traditional mode.

It can be clearly seen that under optimizing control mode, negative power was inhibited to almost 0 , while under the traditional control mode, the negative power did not fall, therefore, the index of negative power is also significantly improved under optimal control.

\subsubsection{Comparison and Summary of the Changes}

The other situations are similar to the result of Figure 7a,b. In Table 3, we directly give the comparison of three indexes, (1) is the optimization control mode, and (2) is the traditional control mode.

Table 3. Comparison of indexes under each transient DAB model.

\begin{tabular}{|c|c|c|c|}
\hline \multicolumn{4}{|c|}{$500 \mathrm{~W} \rightarrow 250 \mathrm{~W}$} \\
\hline & $i_{L(r m s)}(\mathrm{A})$ & $\left|I_{d c}\right|(\mathrm{A})$ & $P_{-a v g}(\mathrm{~W})$ \\
\hline (1) & 16.86 & 0.4893 & -0.1567 \\
\hline (2) & 19.91 & 1.146 & -225 \\
\hline \multicolumn{4}{|c|}{$500 \mathrm{~W} \rightarrow 300 \mathrm{~W}$} \\
\hline & $i_{L(r m s)}(\mathrm{A})$ & $\left|I_{d c}\right|(\mathrm{A})$ & $P_{-a v g}(\mathrm{~W})$ \\
\hline (1) & 16 & 0.677 & -1.058 \\
\hline (2) & 20.04 & 1.126 & -209 \\
\hline \multicolumn{4}{|c|}{$500 \mathrm{~W} \rightarrow 350 \mathrm{~W}$} \\
\hline & $i_{L(r m s)}(\mathrm{A})$ & $\left|I_{d c}\right|(\mathrm{A})$ & $P_{-a v g}(\mathrm{~W})$ \\
\hline (1) & 17.41 & 0.6871 & -9.099 \\
\hline (2) & 20.17 & 0.9325 & -194.4 \\
\hline \multicolumn{4}{|c|}{$500 \mathrm{~W} \rightarrow 400 \mathrm{~W}$} \\
\hline & $i_{L(r m s)}(\mathrm{A})$ & $\left|I_{d c}\right|(\mathrm{A})$ & $P_{-a v g}(\mathrm{~W})$ \\
\hline (1) & 18.28 & 0.6143 & -27.74 \\
\hline (2) & 20.29 & 0.6808 & -180.3 \\
\hline \multicolumn{4}{|c|}{$500 \mathrm{~W} \rightarrow 450 \mathrm{~W}$} \\
\hline & $i_{L(r m s)}(\mathrm{A})$ & $\left|I_{d c}\right|(\mathrm{A})$ & $P_{-a v g}(\mathrm{~W})$ \\
\hline (1) & 20.06 & 0.6302 & -79.41 \\
\hline (2) & 20.41 & 0.9902 & -165.9 \\
\hline \multicolumn{4}{|c|}{$500 \mathrm{~W} \rightarrow 550 \mathrm{~W}$} \\
\hline & $i_{L(r m s)}(\mathrm{A})$ & $\left|I_{d c}\right|(\mathrm{A})$ & $P_{-a v g}(\mathrm{~W})$ \\
\hline (1) & 21.51 & 0.7485 & -160 \\
\hline (2) & 22.54 & 1.116 & -257.2 \\
\hline
\end{tabular}

Three contrastive curves are drawn in Figure 10 from Table 3: (the transverse axis indicates a transient variation from the rated power of $500 \mathrm{~W}$ to the corresponding power). 


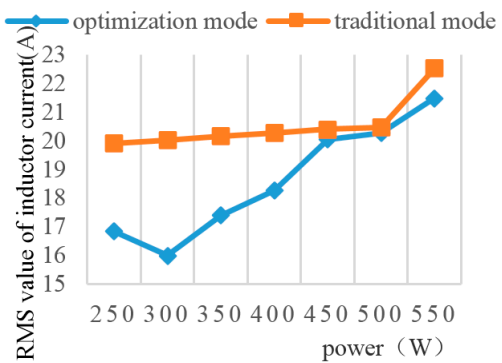

(a)

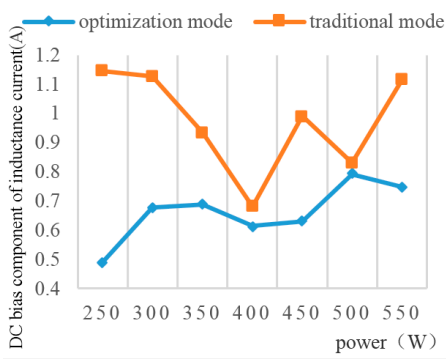

(b)

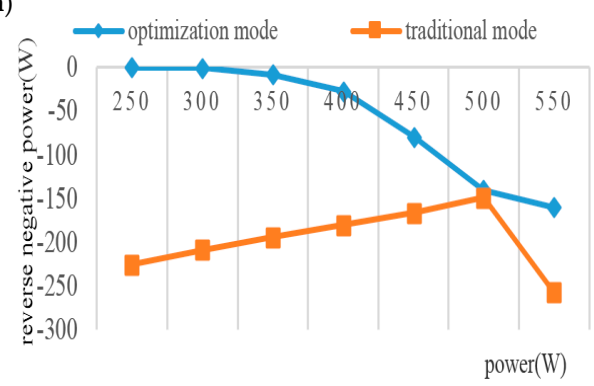

(c)

Figure 10. Three contrastive curves according to Table 3. (a) Comparison of RMS value of inductor current; (b) Comparison of DC bias component of inductance current; (c) Comparison of reverse negative power.

The comparison in Figure 10 shows that, under the rated power, the indicators of the two kinds of control modes are similar, but when the load changes, the performance index of the optimized control mode is obviously superior to the traditional control mode.

\subsection{Typhoon Hard-in-Loop Simulation Verification}

The Typhoon HIL system provides a complete solution to engineers doing research and design of power electronics systems on one system (platform) for engineering project design, real-time simulation, verification and real-time testing. Figure 11a is the hardware block diagram of the Typhoon HIL system [26].

The main circuit of the system is built on the Typhoon platform, as shown in Figure 11b, and the semi physical simulation experiment is carried out in combination with the control program in the DSP28335 (Delfino, Texas Instruments, Dallas, TX, USA). Like the MATLAB simulation, the load resistance increases from $1.568 \Omega$ to $3.136 \Omega$ at $0.05 \mathrm{~s}$, and the transmission power is changed from the rated $500 \mathrm{~W}$ to $250 \mathrm{~W}$. Observe the performance under the load transient variation.

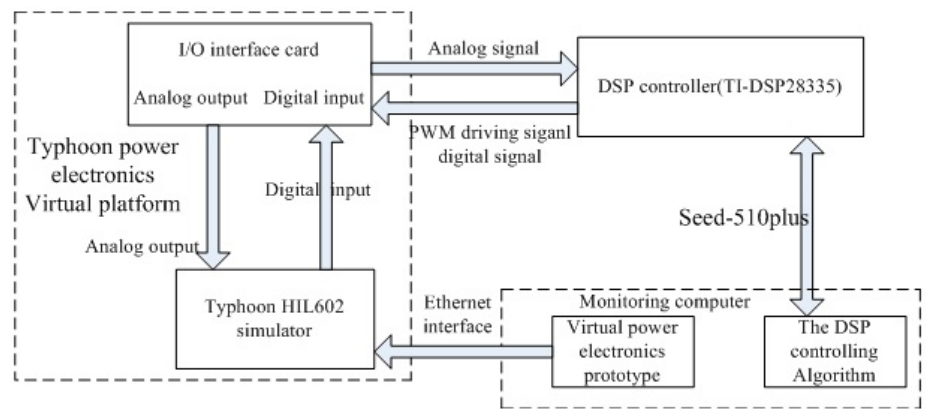

(a)

Figure 11. Cont. 


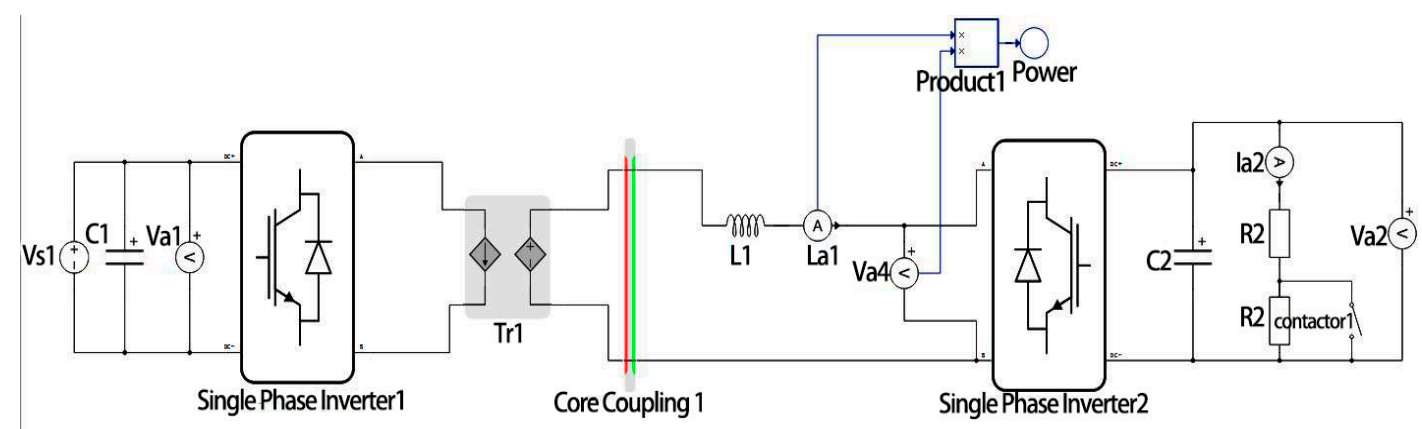

(b)

Figure 11. (a) The hardware block diagram of the Typhoon HIL system; (b) Typhoon based converter virtual hardware circuit in software platform.

\subsubsection{Output Voltage Performance}

The DAB converter is connected with pure resistive load in accordance with the parameters given in Table 1. The waveform at the output terminal of DAB converter is shown in Figure 12a under the rated steady state. The red waveform represents the output voltage. The green one is output current waveform.

It is shown that the converter response time is about $7 \mathrm{~ms}$, there is no overshoot and output voltage is stable at $28 \mathrm{~V}$, ripple voltage is about $0.04 \mathrm{~V}$, the ripple ratio is $0.14 \%$, output current is about $17.86 \mathrm{~A}$, the current ripple is about $0.04 \mathrm{~A}$, the ripple ratio is $0.22 \%$, output power reaches $500 \mathrm{~W}$, reached the requirements.

After the load is abruptly changed, the output voltage and current waveform are shown in Figure 12b. After the load transient variation, the voltage drops slightly, but it remains near $28 \mathrm{~V}$, the current is about $8.86 \mathrm{~A}$, and the power is about $250 \mathrm{~W}$.

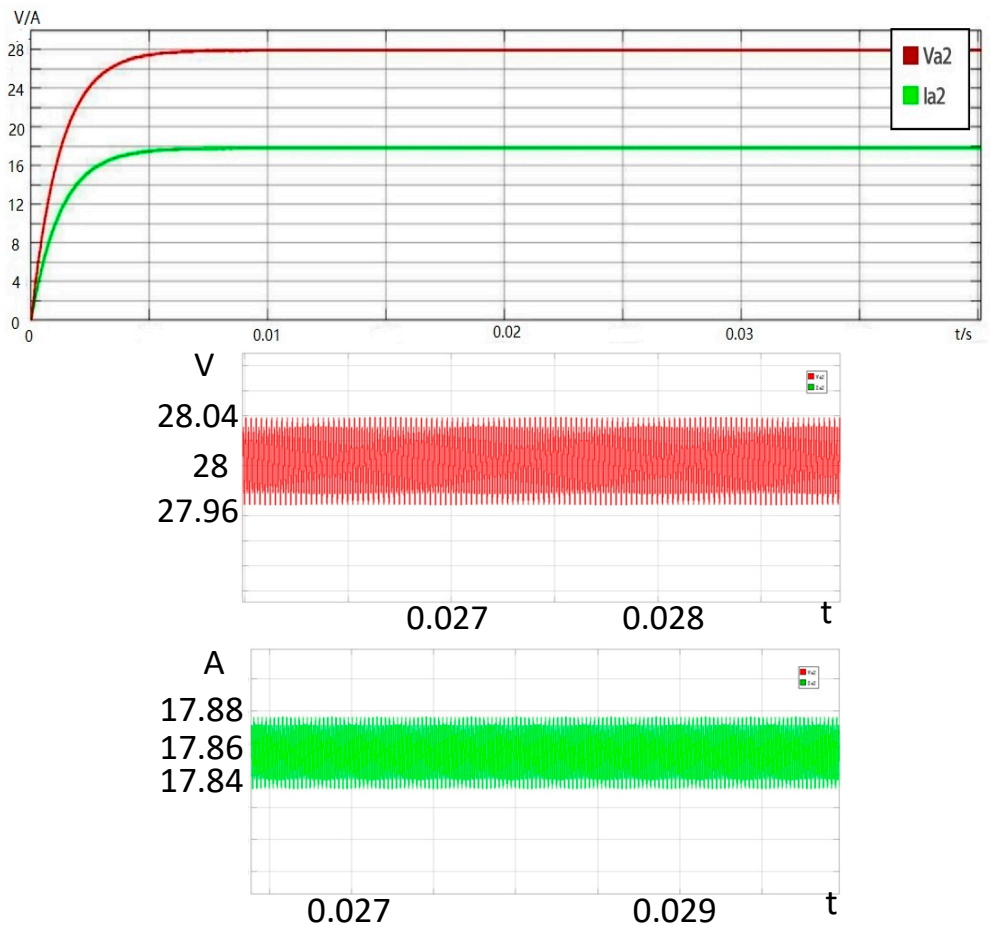

(a)

Figure 12. Cont. 


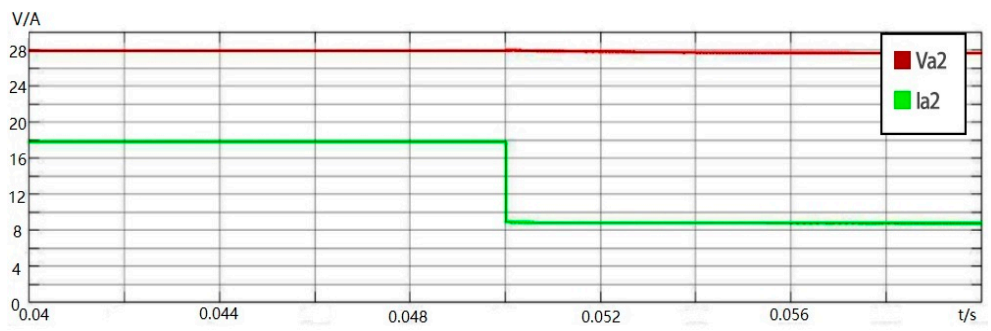

(b)

Figure 12. Output waveform. (a) output voltage, current waveform and local magnification diagram under optimal control mode; (b) Output waveform in the case of load transient variation.

\subsubsection{Realization of Soft Switching}

The operation of switch $Q_{1} \& S_{1}$ is shown in Figure 13. Figure 13a is the turn on waveform of $S_{1}$. Under rated working conditions, the voltage $V_{D S}$ when the switch is off is $270 \mathrm{~V}$, and the drive voltage of switch, $V_{G S}$ is $1 \mathrm{~V}$. At the moment of $S_{1}$ opening, the $S_{2}$ has been turned off, the inductance current is negative, and the anti-parallel diode of $S_{1}, S_{D 1}$ is used to continue the current, thus, the zero voltage opening conditions are met. The red waveform is the switching waveform of device S1 and Q1. The green one is the waveform of inductance current.

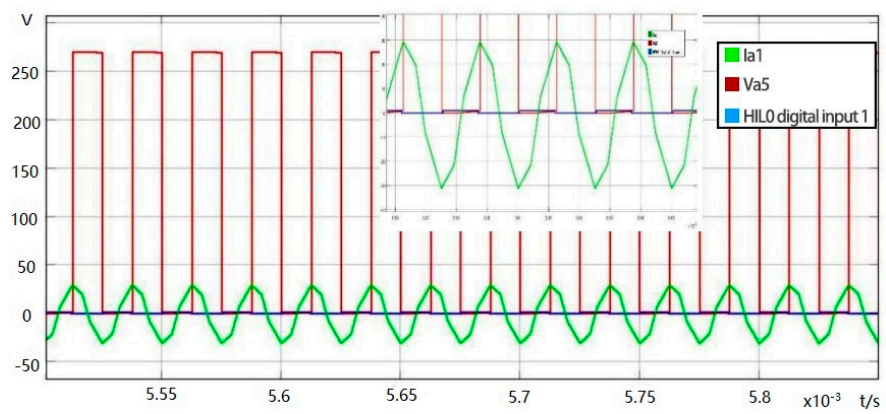

(a)

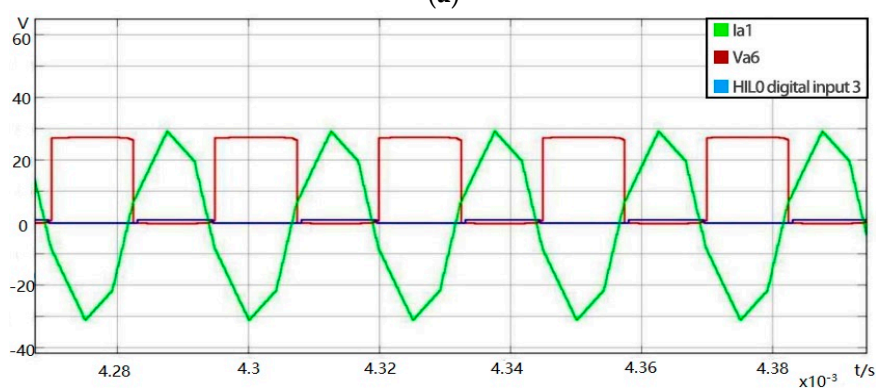

(b)

Figure 13. Realization of soft switch (a); turn on waveform of $S_{1}(\mathbf{b})$ turn on waveform of $Q_{1}$.

Figure $13 \mathrm{~b}$ is the open waveform of $Q_{1}$. Under rated working condition, the voltage $V_{D S}$ when the switch is off is $28 \mathrm{~V}$, and the drive voltage of switch, $V_{G S}$ is $1 \mathrm{~V}$. At the moment of $Q_{1}$ opening, the $Q_{2}$ has been turned off, the inductance current is negative, and the anti-parallel diode of $Q_{1}, Q_{D 1}$ is used to continue the current, thus, the zero voltage opening conditions are meet. The other switches are similar to the above waveforms, and therefore are omitted here.

\subsubsection{Coupled Inductor Related Waveforms}

Figure 14 is an inductive voltage waveform, which is in agreement with the theoretical analysis. 


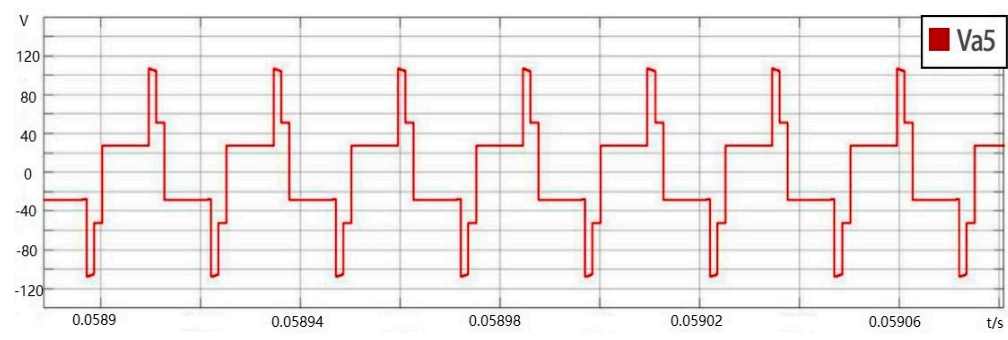

Figure 14. Inductance voltage waveforms.

Figure $15 \mathrm{a}, \mathrm{b}$ are the inductance current waveforms of the steady-state and load abrupt moments, which are same with the low voltage side current waveforms of transformer. As can be seen from Figure 15a, the current waveform of the inductor is in agreement with the theoretical analysis. As can be seen from Figure 15b, after the load is abruptly changed, the inductance current is restored to positive and negative symmetry after about $0.0004 \mathrm{~s}$, and the peak and peak value decrease from $\pm 30 \mathrm{~V}$ to $\pm 20 \mathrm{~V}$. By calculation the RMS value of the inductor current is $16.88 \mathrm{~A}$, and the DC bias component is about $0.4903 \mathrm{~A}$.

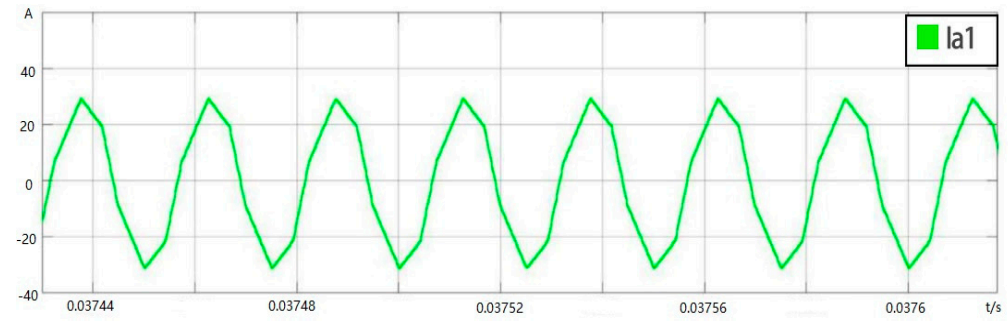

(a)

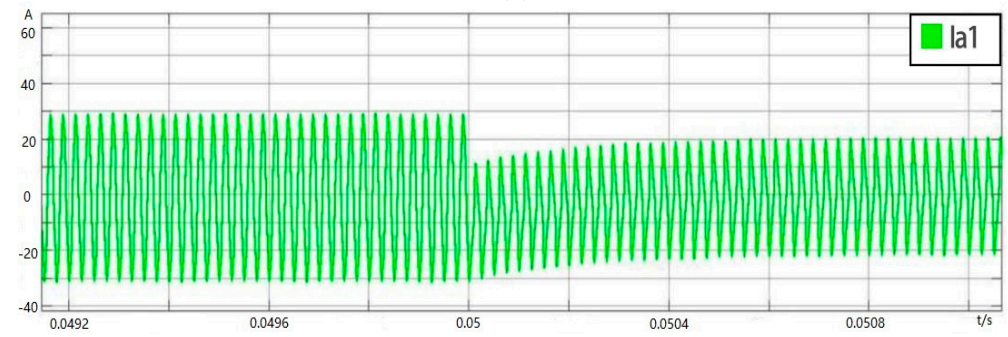

(b)

Figure 15. Inductance current waveforms on (a) Steady state; (b) transient state.

\subsubsection{Transformer Related Waveform}

Figure 16 is the voltage waveform of the low voltage side of the transformer, with an amplitude of $\pm 80 \mathrm{~V}$, and the waveform is consistent with the theoretical analysis.

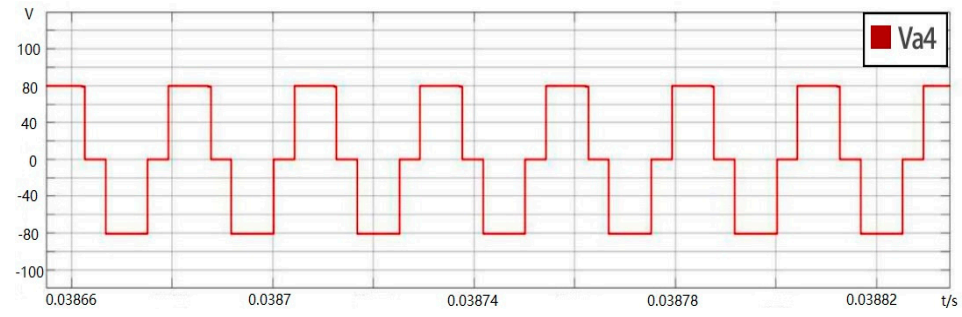

Figure 16. Voltage waveform of low voltage side of transformer.

Figure 17 is the power waveforms of the low voltage side of the transformer at the steady-state and load abrupt variation moments. 


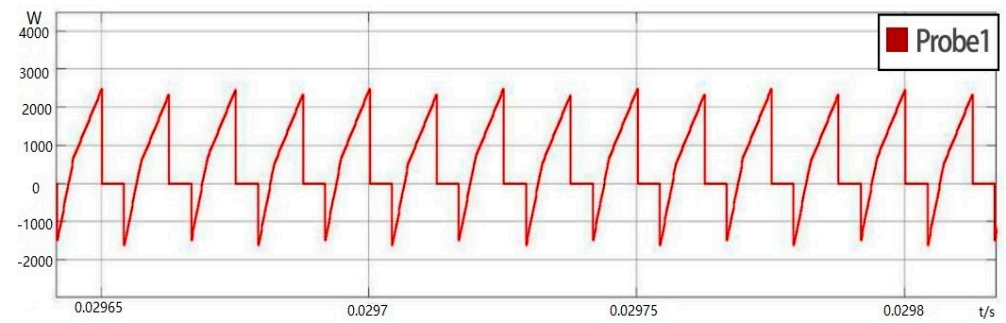

(a)

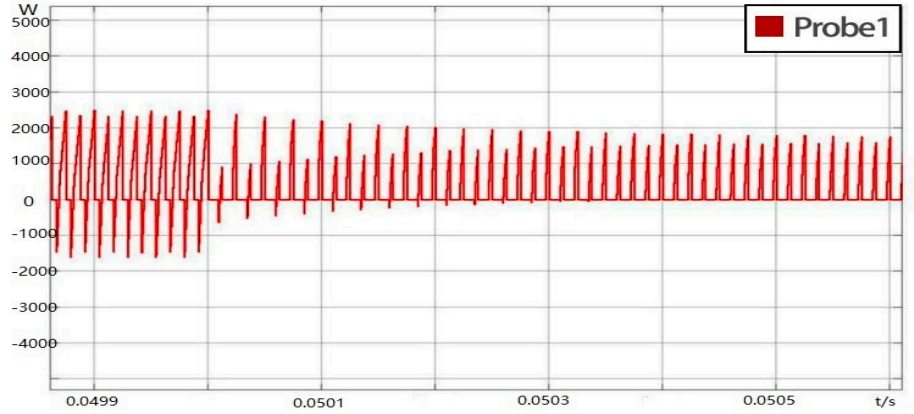

(b)

Figure 17. The power waveforms of the low voltage side of the transformer on (a) Steady state; (b) transient state.

Due to the role of the external phase angle $D_{2}$, the phase of the transformer's current and voltage is not synchronous in Figures 15a and 16, which results in a negative value of the instantaneous power of the transformer, that is, the reverse negative power phenomenon. However, from Figure 16, we can see that because of the presence of $D_{1}$, the output voltage has zero output time. In this period, the negative power has changed to 0 , which reduces the size of negative power and improves the efficiency of energy transmission. It can be seen from Figure $17 \mathrm{~b}$ that the reverse negative power is suppressed after the load mutation, and after 12 cycles, about $0.3 \mathrm{~ms}$, the negative power is almost $0 \mathrm{~W}$.

\section{Verification of Experiment Prototype Hardware}

A prototype DAB converter was designed for verification of the proposed scheme. A 200-600 W scaled down DAB converter has been developed. The schematic layout of experimental set-up is presented in Figure 18. During the experimentation, an aerospace high voltage DC source (270 V DC) was used for power supply. In the DAB converter, the power switching device in high voltage side was a International Rectifier-MOSFET IRF460P (Infineon Technologies AG, Neubiberg, Germany), and on the low voltage side it is an IRF150P.

The experimental verification of DAB converter is carried out by using a DSP28335 DSP digital controller, All the control algorithms were downloaded into this controller. The results of the experiments are shown in Figure 19. From Figure 19a, the steady state characteristic for the output voltage can be achieved by the proposal controlling methods based on the multi-objective optimization. In Figure 19b,c, it is can been seen that the inductance current can charge and discharge following the control logic signal under the optimization methods. The power transmission can be achieved according to Figure 19c. When the input voltage is $273 \mathrm{~V}$, the output voltage is $27.9 \mathrm{~V}$. In order to verify the transient ability of the control algorithm, the transient load variation was carried out, with the experimental results shown in Figure 19d, and the output voltage can be quickly kept at reference voltage of $28 \mathrm{~V}$. 


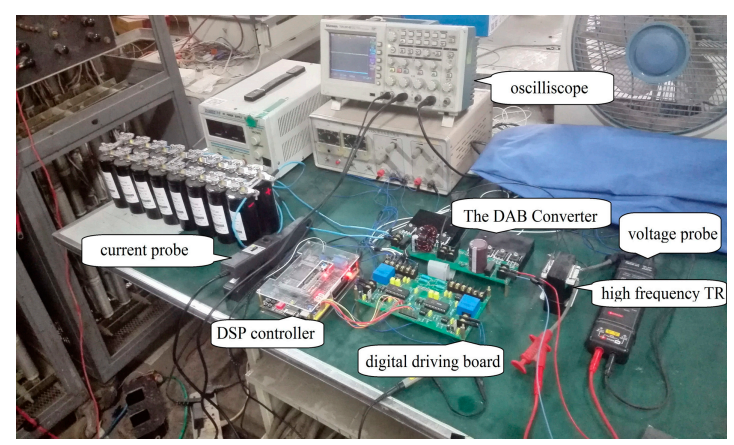

Figure 18. The experimental prototype diagram.

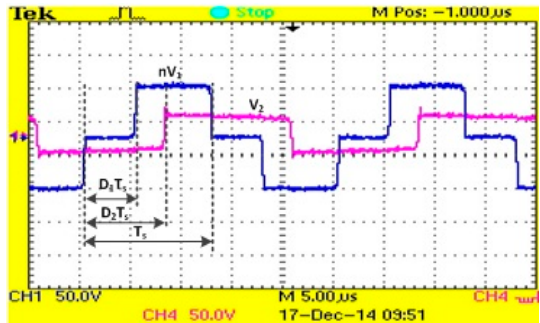

(a)

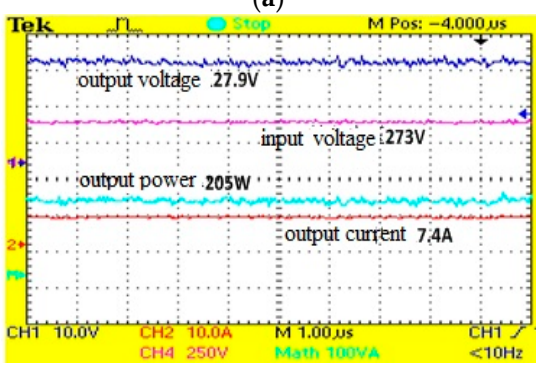

(c)

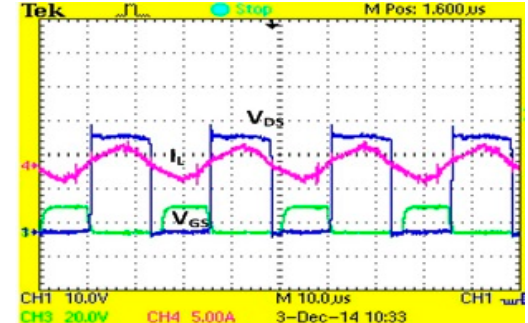

(b)

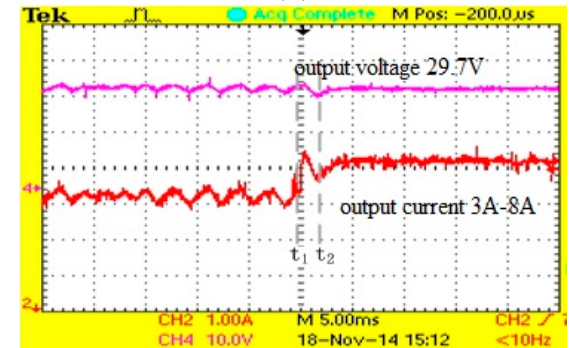

(d)

Figure 19. (a) The steady state waveform of input and output voltage; (b) The MOSFET gate driving signal and inductor current waveform; (c) Output characteristic waveform of power and voltage; (d) The transient waveform of output voltage under load variation.

In order to verify the capability of the proposed method to decrease the reverse negative power transmission, a comparative experiment was carried out under the two control methods, for the traditional double phase shift and the proposed method, respectively. It can be seen from Figure 20 that the reverse negative power can be greatly reduced. It is verified that the proposed methods are valid and reliable enough for use in the DAB converter in an aircraft electric power system background.

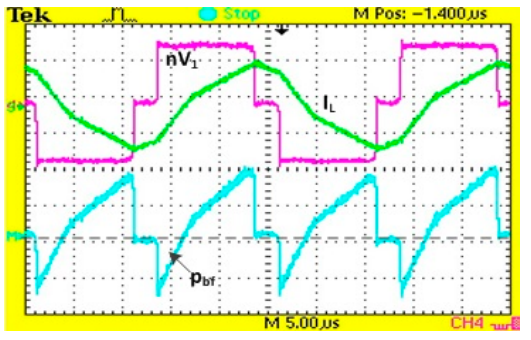

(a)

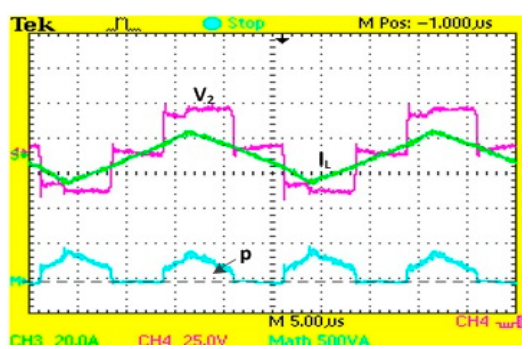

(b)

Figure 20. The waveform of transmission power in (a) Traditional control methods (b) The proposed methods. 
According to the different performance index testing methods, the aerospace DAB converter's experimental result comparison under different control methods can be showed in Figure 21. From Figure 21, the DAB converter's performance features such as the inductance current RMS can be minimized based on the optimization control method. The DC-bias current for the high frequency transformer can be suppressed greatly to avoid the saturation of the iron core of the transformer. The reverse negative power was also greatly reduced based on the optimization control methods, which can improve the efficiency of DAB converter. The experimental result can match the result from the simulation result.

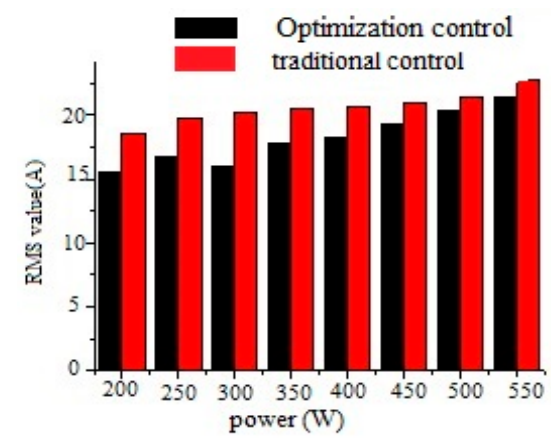

(a)

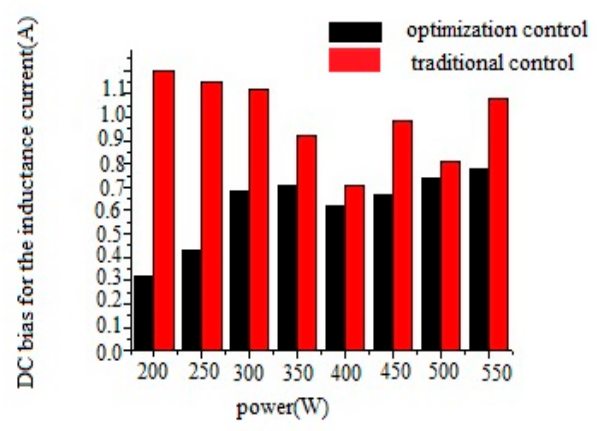

(b)

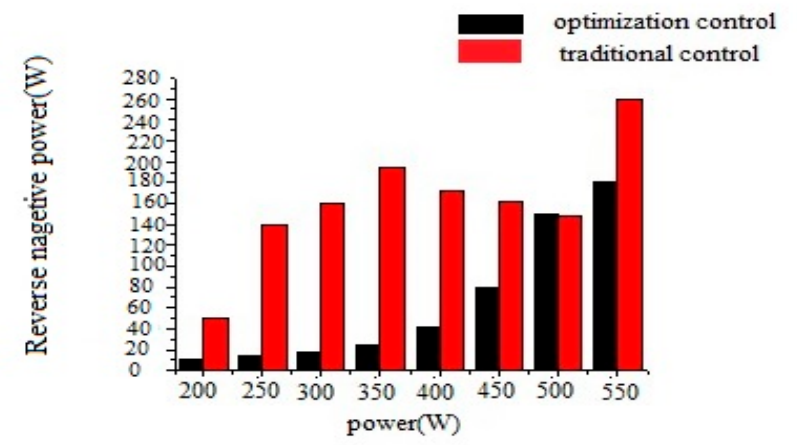

(c)

Figure 21. Experimental result for comparison between the optimization control and traditional control methods (a) RMS value of inductance current (b) DC bias for transformer current (c) Reverse negative power.

\section{Conclusions}

Based on requirements of aviation, this paper designs a dual active bridge DC-DC converter with an extended phase shifting control strategy. The interior and external phase angle are used as the design variables, taking three indexes-the inductor current RMS, transformer reverse negative power and DC bias component-as the optimization goal. The optimization model is established with soft switching as the main constraint. The genetic algorithm optimization toolbox in MATLAB is used to solve the optimal control variable of the DAB converter optimization model. According to the results of simulation and experiments based on the MATLAB/Simulink platform, the Typhoon HIL platform and a hardware prototype, the three indexes have been effectively improved, and the rationality of the optimization method is verified. The next step for this research topic is to analyze the relationship between the different optimal objects, and simplify the optimal power model for the DAB converter. Based on this, the aim is to explore the real-time selection method of the optimal solution and realize online optimization control of the DAB converter. 
Author Contributions: Tao Lei and Cengying Wu proposed the Multi-objective optimization control strategy; Cengying $\mathrm{Wu}$ build the simulation model for the DAB converter; Xaiofei Liu and Tao Lei performed the experiments for $\mathrm{DAB}$ converter; Cengying $\mathrm{Wu}$ and Tao Lei analyzed the simulation and experimental data; Tao Lei, Cengying $\mathrm{Wu}$, and Xaiofei Liu wrote the paper.

Conflicts of Interest: The authors declare no conflict of interest.

\section{References}

1. Boucher, R.J. Sunrise, the world's first solar-powered airplane. J. Aircraft. 2015, 22, 840-846. [CrossRef]

2. Ortiz, G.; Uemura, H.; Bortis, D.; Kolar, J.W.; Apeldoorn, O. Modeling of Soft-Switching Losses of IGBTs in High-Power High-Efficiency Dual-Active-Bridge DC/DC Converters. IEEE Trans. Electron Devices 2013, 60, 587-597. [CrossRef]

3. Cougo, B.; Meynard, T.; Schneider, H. Reconfigurable Dual Active Bridge Converter for Aircraft Application. In Proceedings of the IEEE Electrical Systems for Aircraft, Railway and Ship Propulsion (ESARS), Bologna, Italy, 16-18 October 2012; pp. 1-6.

4. Naayagi, R.T.; Forsyth, A.J.; Shuttleworth, R. High-power Bidrectional DC-DC Converter for Aerospace Applications. IEEE Trans. Power Electron. 2012, 27, 4366-4379. [CrossRef]

5. Sarlioglu, B. Advances in AC-DC power conversion topologies for More Electric Aircraft. In Proceedings of the Transportation Electrification Conference and Expo, Dearborn, MI, USA, 18-20 June 2012; pp. 1-6.

6. Naayagi, R.T. A review of more electric aircraft technology. In Proceedings of the International Conference on Energy Efficient Technologies for Sustainability, Nagercoil, India, 10-12 April 2013; pp. 750-753.

7. Engel, S.P.; Soltau, N.; Stagge, H.; De Doncker, R.W. Dynamic and Balanced Control of Three-Phase High-Power Dual-Active Bridge DC-DC Converters in DC-Grid Applications. IEEE Trans. Power Electron. 2013, 28, 1880-1889. [CrossRef]

8. Zhao, B.; Yu, Q.; Sun, W. Extended-Phase-Shift Control of Isolated Bidirectional DC-DC Converter for Power Distribution in Microgrid. IEEE Trans. Power Electron. 2012, 27, 4667-4680. [CrossRef]

9. Krismer, F.; Kolar, J.W. Closed Form Solution for Minimum Conduction Loss Modulation of DAB Converters. IEEE Trans. Power Electron. 2011, 27, 174-188. [CrossRef]

10. Krismer, F.; Kolar, J.W. Efficiency-Optimized High-Current Dual Active Bridge Converter for Automotive Applications. IEEE Trans. Ind. Electron. 2012, 59, 2745-2760. [CrossRef]

11. Shen, Y.; Sun, X.; Li, W.; Wu, X.; Wang, B. A Modified Dual Active Bridge Converter with Hybrid Phase-Shift Control for Wide Input Voltage Range. IEEE Trans. Power Electron. 2016, 31, 6884-6900. [CrossRef]

12. Choi, W.; Rho, K.M.; Cho, B.H. Fundamental Duty Modulation of Dual-Active-Bridge Converter for Wide-Range Operation. IEEE Trans. Power Electron. 2016, 31, 4048-4064. [CrossRef]

13. Taylor, A.; Liu, G.; Bai, H.; Brown, A.; Johnson, P.M.; McAmmond, M. Multiple-Phase-Shift Control for Dual Active Bridge to Secure Zero-Voltage Switching and Enhance Light-Load Performance. IEEE Trans. Power Electron. 2018, 33, 4584-4589. [CrossRef]

14. Tong, A.; Hang, L.; Li, G.; Jiang, X.; Gao, S. Modeling and Analysis of Dual-Active-Bridge Isolated Bidirectional DC/DC Converter to Minimize RMS Current. IEEE Trans. Power Electron. 2018, 33, 5302-5316. [CrossRef]

15. Filba-Martinez, A.; Busquets-Monge, S.; Nicolas-Apruzzese, J.; Bordonau, J. Operating Principle and Performance Optimization of a Three-Level NPC Dual-Active-Bridge DC-DC Converter. IEEE Trans. Ind. Electron. 2016, 63, 678-690. [CrossRef]

16. Zhao, B.; Song, Q.; Liu, W.; Sun, W. Current-Stress-Optimized Switching Strategy of Isolated Bidirectional DC-DC Converter With Dual-Phase-Shift Control. IEEE Trans. Ind. Electron. 2013, 60, 4458-4467. [CrossRef]

17. Akter, P.; Uddin, M.; Mekhilef, S.; Tan, N.M.L.; Akagi, H. Model predictive control of bidirectional isolated DC-DC converter for energy conversion system. Int. J. Electron. 2015, 102, 1407-1427. [CrossRef]

18. Saeed, J.; Hasan, A. Unit Prediction Horizon Binary Search-Based Model Predictive Control of Full-Bridge DC-DC Converter. IEEE Trans. Control Syst. Technol. 2018, 26, 463-473. [CrossRef]

19. Tong, A.; Hang, L.; Guojie, L.I. Global Optimized Control Strategy of Dual Active Bridge Converter Controlled by Triple-phase-shift Modulation Scheme and Its Analysis. Proc. CSEE 2017, 37, 6037-6049. 
20. Burkart, R.M.; Kolar, J.W. Comparative $\eta-\rho-\sigma$ Pareto Optimization of Si and SiC Multilevel Dual-Active-Bridge Topologies with Wide Input Voltage Range. IEEE Trans. Power Electron. 2017, 32, 5258-5270. [CrossRef]

21. Chakraborty, S.; Chattopadhyay, S. Minimum-RMS-Current Operation of Asymmetric Dual Active Half-Bridge Converters with and Without ZVS. IEEE Trans. Power Electron. 2017, 32, 5132-5144. [CrossRef]

22. Zhang, K.; Shan, Z.; Jatskevich, J. Large- and Small-Signal Average Value Modeling of Dual-active-bridge DC-DC Converter Considering Power Losses. IEEE Trans. Power Electron. 2017, 32, 1964-1974. [CrossRef]

23. Zhao, B.; Song, Q.; Liu, W. Efficiency Characterization and Optimization of Isolated Bidirectional DC-DC Converter Based on Dual-Phase-Shift Control for DC Distribution Application. IEEE Trans. Power Electron. 2013, 28, 1711-1727. [CrossRef]

24. Shao, C.W.; Wang, S.Z. Function Analysis of Biasing and Its Restriction Technique in Full Bridge Converter. Electrotech. Electr. 2012, 1, 4.

25. Zhao, B.; Song, Q.; Liu, W.; Zhao, Y. Transient DC Bias and Current Impact Effects of High-Frequency-Isolated Bidirectional DC-DC Converter in Practice. IEEE Trans. Power Electron. 2016, 31, 3203-3216. [CrossRef]

26. Typhoon HIL 600 User Manual. Available online: https://www.typhoon-hil.com/products/hil604 (accessed on 19 May 2016).

(C) 2018 by the authors. Licensee MDPI, Basel, Switzerland. This article is an open access article distributed under the terms and conditions of the Creative Commons Attribution (CC BY) license (http://creativecommons.org/licenses/by/4.0/). 